\title{
The effect of concrete composition on laser scabbling
}

\author{
B. Peach ${ }^{\mathrm{a}, 1, * *}$, M. Petkovski ${ }^{\mathrm{a}, 2, *}$, J. Blackburn $^{\mathrm{b}}$, D.L. Engelberg ${ }^{\mathrm{c}}$ \\ ${ }^{a}$ Department of Civil and Structural Engineering, Sir Frederick Mappin Building, Mappin Street, University of Sheffield, Sheffield, S1 3JD, UK \\ ${ }^{b}$ TWI Ltd, Granta park, Great Abington, Cambridge, CB21 6AL, UK \\ ${ }^{c}$ Research Centre for Radwaste $\mathcal{E}$ Decommissioning, School of Materials, The University of Manchester, Manchester, M13 9PL, UK
}

\begin{abstract}
Laser concrete scabbling is the process by which the surface layer of concrete may be removed through the use of a low power density laser beam. The main aim of this investigation was to establish relationships between laser interaction time and volume removal for a wide range of material compositions, including different $\mathrm{w} / \mathrm{b}$ ratios, binder compositions (OPC/PFA), aggregate/binder ratios and coarse aggregate sizes. The results show that $25 \%$ replacement of ordinary Portland cement with pulverised fuel ash and/or a reduced water/binder ratio improves the efficiency of scabbling of cement pastes. Mortars and cement pastes were seen to scabble at a constant rate, whereas concretes experienced a peak rate, after which volume removal reduced dramatically. Basalt aggregate concrete was less susceptible to laser scabbling than limestone aggregate concrete. The effects of composition on the mechanisms which drive laser scabbling are discussed. It is suggested that pore pressure spalling governs behaviour in cement pastes, and thermal stress spalling is more dominant in mortar specimens. The driving force responsible for laser scabbling of concretes is developed within the mortar.
\end{abstract}

Keywords:

Concrete, Cement, Scabbling, Spalling, Thermal Analysis

\section{Introduction}

This paper describes the second part of an investigation of the mechanisms responsible for laser scabbling; a technique for removal of the surface layer of concrete which can be used for decontamination in nuclear decommissioning. Radioactive contamination in concrete is generally limited to a depth of around $10 \mathrm{~mm}$ [1]. Application of a low power density laser, perpendicular to the concrete surface, causes concrete fragments to be ejected, thus reducing the volume of radioactive waste sent for disposal. This technique is preferable to alternative methods, such as mechanical scabbling or high pressure water jetting, as no reaction forces or secondary wastes are created.

\footnotetext{
${ }^{*}$ Corresponding author

** Principal corresponding author

Email addresses: bdpeach1@sheffield.ac.uk (B. Peach), m.petkovski@sheffield.ac.uk (M. Petkovski), jon.blackburn@twi.co.uk (J. Blackburn), dirk.engelberg@manchester.ac.uk (D.L. Engelberg)

${ }^{1}$ Tel: +44 (0) 1142225729

${ }^{2}$ Tel: +44 (0) 1142225759
}

As concrete is exposed to extreme heat rates such as those induced during laser scabbling, there are many interlinked phenomena taking place simultaneously. It is assumed that laser scabbling can not be attributed to any one mechanism but to a complex combination of coupled hygro-chemo-thermo-mechanical effects. In the first part of this investigation [2], a wide range of materials were investigated with an aim to establish an experimental procedure for quantification of the relationships between laser interaction time, surface temperature, volume removal and size of fragments. Materials tested included hardened cement pastes, aggregate rock, mortars and concretes, as well as two different levels of saturation. The first test series set out the experimental technique and identified parameters to be investigated in further experimental programmes.

The results of the first series [2] showed that:

1. The use of PFA as a cement replacement material $(75 \%$ OPC $+25 \%$ PFA) enhanced volume removal during laser scabbling of hardened cement paste (this was attributed to reduced permeability of the material);

2. Volume removal of mortars was higher than that of 
Table 1: The scopes of the 1st series [2] and the 2 nd series (presented in this paper)

\begin{tabular}{lcc}
\hline & 1st series [2] & 2nd series \\
\hline \hline$w / b$ ratio of cement pastes & 0.42 & $0.32 \& 0.42$ \\
\hline $\begin{array}{l}\text { Binder of concretes and } \\
\text { mortars }(O P C \% / P F A \%)\end{array}$ & $75 / 25$ & $75 / 25 \& 100 / 0$ \\
\hline Coarse aggregate size & $10 \mathrm{~mm}$ & $10 \mathrm{~mm} \& 20 \mathrm{~mm}$ \\
\hline Laser interaction time intervals & $10 \mathrm{~s}, 40 \mathrm{~s}$ & $5 \mathrm{~s}, 10 \mathrm{~s}, 20 \mathrm{~s}, 30 \mathrm{~s}, 40 \mathrm{~s}, 50 \mathrm{~s}, 70 \mathrm{~s}$ \\
\hline
\end{tabular}

concretes and similar to that of PFA + OPC pastes, but with larger fragment sizes;

3. Results were repeatable, there was no evidence of stochastic tendencies reported in previous studies $[3,4,5,6]$;

4. Basalt concrete scabbled more than in any previous study [3, 4], but still less than limestone concrete;

5. Reducing the degree of saturation of specimens (saturated vs. air-dried) did not reduce scabbling.

\section{Scope and aim of the research}

This paper aims to determine the relationship between laser interaction time, volume removal and surface temperatures for different compositions in order to identify the effect of concrete composition on laser scabbling behaviour (rate of volume removal, temperature at the onset of scabbling, surface temperature during scabbling, fragment ejection frequency and fragment sizes, as seen in Figure 1). These observations were then used to assess the effect of each parameter and form conclusions on the potential mechanisms responsible for laser scabbling.

The compositions selected for investigation in this study were designed to isolate factors of the laser scabbling process identified from the first test series [2], the scopes of the two test series are presented in Table 1.

The compositions tested in this series are as follows:

1. Cement pastes with different $w / b$ ratios were investigated to determine the effects of permeability and strength on laser scabbling;

2. Concretes, mortars and hardened cement pastes with two different binder compositions (OPC and PFA + OPC) were analysed to determine the effect of PFA replacement in different materials;

3. Limestone and basalt aggregate concretes using OPC and PFA + OPC binders were tested to characterise the effect of different aggregate/binder combinations;

4. Concretes with two coarse aggregate gradings (10 $\mathrm{mm}$ and $20 \mathrm{~mm}$ ) were tested to determine the effect of aggregate size;

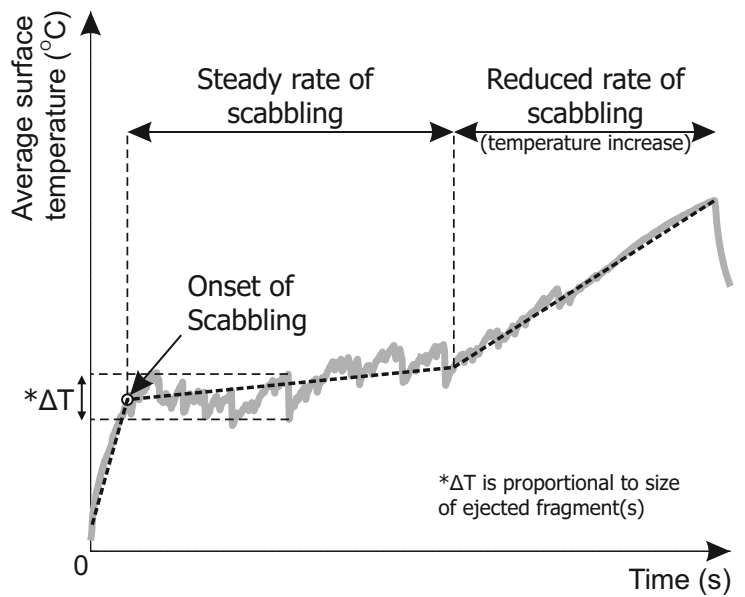

Figure 1: Example average surface temperature graph, showing trilinear behaviour with different stages of scabbling behaviour highlighted.

5. A wide range of interaction times were applied to each composition to determine the relationship between laser interaction time and volume removal for each composition (10 s and $40 \mathrm{~s}$ were used in the first series).

\section{Materials, specimens, test set-up and experimen- tal programme}

The material compositions used in this study are given in Table 2. The materials used for preparing the test specimens were: Hanson CEM 1 OPC (BS EN 197-1:2000 strength class 52.5 N); CEMEX PFA (LOI-B and fineness-s); fully graded marine dredged quartzitic sand from Hoyle Bank, Morecombe Bay, UK; crushed basalt rock sourced from High Force Quarry, Durham, UK; and crushed limestone rock from Longcliffe Quarry, Derbyshire, UK. Limestone and basalt rock, sourced from the same quarries as the crushed aggregates, was machined to form the rock specimens (100 mm x $100 \mathrm{~mm} \times 49 \mathrm{~mm}+/-1 \mathrm{~mm})$.

All mixes underwent 30-60 seconds dry mixing followed by 3-5 minutes wet mixing. The slurry was trans- 
Table 2: Mix compositions (all measurements in mass:binder ratio unless otherwise stated. * AGR mix is included for comparison only; not tested in the experimental programme. $* *$ Basalt and Limestone Concrete refer to concrete mixes using basalt and limestone as coarse aggregates.)

\begin{tabular}{|c|c|c|c|c|c|c|c|c|c|c|c|}
\hline & \multirow[t]{2}{*}{ *AGR } & \multicolumn{2}{|c|}{ **Lime. Concrete } & \multicolumn{2}{|c|}{ **Bas. Concrete } & \multicolumn{2}{|c|}{ Mortar } & \multicolumn{2}{|c|}{ PFA + OPC Paste } & \multicolumn{2}{|c|}{ OPC Paste } \\
\hline & & $(\mathrm{Lp})$ & (Lo) & (Bp) & (Bo) & (Mp) & (Mo) & $\left(\mathrm{P}_{42}\right)$ & $\left(\mathrm{P}_{32}\right)$ & $\left(\mathrm{O}_{42}\right)$ & $\left(\mathrm{O}_{32}\right)$ \\
\hline Water & 0.42 & 0.42 & 0.42 & 0.42 & 0.42 & 0.42 & 0.42 & 0.42 & 0.32 & 0.42 & 0.32 \\
\hline OPC & 0.75 & 0.75 & 1 & 0.75 & 1 & 0.75 & 1 & 0.75 & 0.75 & 1 & 1 \\
\hline PFA & 0.25 & 0.25 & 0 & 0.25 & 0 & 0.25 & 0 & 0.25 & 0.25 & & \\
\hline Fine agg. & 1.84 & 1.84 & 1.84 & 1.84 & 1.84 & 1.84 & 1.84 & & & & \\
\hline Plasticiser & 0.0045 & 0.0045 & 0.0045 & 0.0045 & 0.0045 & & & & & & \\
\hline $10 \mathrm{~mm}$ agg. & 1.05 & 3.21 & 3.21 & 3.21 & 3.21 & & & & & & \\
\hline $20 \mathrm{~mm}$ agg. & 2.16 & & & & & & & & & & \\
\hline
\end{tabular}

ferred to $100 \mathrm{~mm}$ cube moulds which were $3 / 4$ filled and vibrated for approximately $10 \mathrm{~s}$ before being filled and vibrated again for approximately $10 \mathrm{~s}$, and the cast face trowelled smooth. All specimens underwent a ten day temperature matched curing regime reaching a peak temperature of $65^{\circ} \mathrm{C}$ after 36 hours, gradually returning to $20{ }^{\circ} \mathrm{C}$ after 240 hours. After curing, the $100 \mathrm{~mm}$ cubes were cut in half using a diamond saw, creating $100 \mathrm{~mm}$ x $100 \mathrm{~mm}$ x $49 \mathrm{~mm}(+/-1 \mathrm{~mm})$ cuboid specimens, which were stored in a mist room at $100 \%$ relative humidity until testing. Concretes using different aggregate sizes had the same mass ratio of coarse aggregates; only the aggregate size used was different. All ' $10 \mathrm{~mm}$ ' aggregates passed a $10 \mathrm{~mm}$ sieve and were retained on a $6 \mathrm{~mm}$ sieve. The $20 \mathrm{~mm}$ aggregates had the particle size distribution as follows: all aggregates passed a $24 \mathrm{~mm}$ sieve, $23 \%$ was retained on a $20 \mathrm{~mm}$ sieve, $66 \%$ on a $14 \mathrm{~mm}$ sieve, $10 \%$ on a $10 \mathrm{~mm}$ sieve and $1 \%$ on a $5 \mathrm{~mm}$ sieve.

The laser interaction times, number of repeats and age of specimens at the time of testing are given in Table 3 for the concretes and Table 4 for the pastes and mortars. Hardened cement paste samples were cast 3 months after the mortar and concrete specimens and as a result underwent less ageing/curing. All scabbling tests were carried out using an IPG Photonics YLS-5000 (5 $\mathrm{kW}) \mathrm{Yb}$-fibre laser. The specimens were subjected to a static, continuous, diverging laser beam with a stand off distance of $340 \mathrm{~mm}$ from the focal point which gave a nominal beam diameter of $60 \mathrm{~mm}$. Tests were conducted with the laser beam applied to a vertical concrete surface to avoid debris falling back onto the specimen during testing (in situ the vacuum used to remove the debris would eliminate this problem).

The change in mass due to laser application was determined as the difference in mass of the specimen measured before and after testing. The mass change was converted to volume by dividing the mass by the density determined in accordance with BS EN12390-7:2009 [7]. The volume removal graphs show the mean of the repeats with maximum/minimum error bars. Porosity, moisture content and degree of saturation were subsequently determined using values found in the density tests.

Porosity $=100 *\left(\left(m_{s a t}-m_{o d}\right) /\left(m_{s a t}-m_{s u b}\right)\right)$,

Moisture content $=100 *\left(\left(m_{t}-m_{o d}\right) / m_{t}\right)$,

Degree of saturation $=100 *\left(\left(m_{t}-m_{o d}\right) /\left(m_{s a t}-m_{o d}\right)\right)$; where $m_{s a t}, m_{o d}, m_{s u b}$ and $m_{t}$ are saturated, oven-dried, submerged and as received masses respectively.

An infrared camera (FLIR SC 640) was used to monitor the surface temperatures; and a high-speed camera (Phantom V5.1) to record the ejection of fragments. The average surface temperature was taken over the surface area that exceeded $100{ }^{\circ} \mathrm{C}$ after $1.0 \mathrm{~s}$ of interaction time. The time histories of average surface temperature, showing the temperature fluctuations due to ejection of fragments (their amplitudes corresponding to size of fragments), were used as key data in characterisation of the scabbling behaviour of each material.

The infrared camera can operate within temperature ranges of $0-550{ }^{\circ} \mathrm{C}$ or $200-2000{ }^{\circ} \mathrm{C}$. If the average surface temperature of a specimen exceeded the lower temperature range of the infrared camera the test was repeated using the higher temperature range. The two data sets were then merged to give data for the whole temperature range over the whole interaction time. Volume removal data is presented with the average surface temperature data on the same timescale. It should be noted that the volume removal data presented are mean values of the repeats for each interaction time tested with $\max / \mathrm{min}$ error bars, and connecting lines are present to guide the eye. The average surface temperature histories, however, are real time temperatures for one or two tests (depending on the temperature ranges required).

To characterise thermal processes that took place during scabbling, differential thermal and thermogravimetric analyses (DTA/TGA) were carried out on scabbled debris and untested control specimens. A Perkin Elmer Star 8000 simultaneous thermal analyser with aluminium oxide pan and aluminium oxide reference 
Table 3: Experimental programme and test specimens: Concretes and rock specimens

\begin{tabular}{|c|c|c|c|c|}
\hline $\begin{array}{l}\text { Test/ } \\
\text { Spec. }\end{array}$ & $\begin{array}{l}\text { Material } \\
\text { Composi- } \\
\text { tion }\end{array}$ & $\begin{array}{c}\text { No. of } \\
\text { Repeats }\end{array}$ & $\begin{array}{l}\text { Int. } \\
\text { time } \\
\text { (s) }\end{array}$ & $\begin{array}{c}\text { Age } \\
\text { (days) }\end{array}$ \\
\hline $\mathrm{Lo}_{10} 5$ & Limestone & 3 & $\overline{5}$ & 207 \\
\hline $\mathrm{Lo}_{10} 10$ & Concrete & 3 & 10 & 207 \\
\hline $\mathrm{Lo}_{10} 20$ & $10 \mathrm{~mm}$ agg. & 3 & 20 & 207 \\
\hline $\mathrm{Lo}_{10} 30$ & (OPC & 3 & 30 & 207 \\
\hline $\mathrm{Lo}_{10} 40$ & binder) & 5 & 40 & 204-211 \\
\hline $\mathrm{Lo}_{20} 5$ & Limestone & 3 & 5 & 207 \\
\hline $\mathrm{Lo}_{20} 10$ & Concrete & 3 & 10 & 207 \\
\hline $\mathrm{Lo}_{20} 20$ & $20 \mathrm{~mm}$ agg. & 3 & 20 & 207 \\
\hline $\mathrm{Lo}_{20} 30$ & (OPC & 4 & 30 & 207 \\
\hline $\mathrm{Lo}_{20} 40$ & binder) & 3 & 40 & $205-207$ \\
\hline $\mathrm{Lp}_{10} 5$ & Limestone & 3 & 5 & 207 \\
\hline $\mathrm{Lp}_{10} 10$ & Concrete & 3 & 10 & 207 \\
\hline $\mathrm{Lp}_{10} 20$ & $10 \mathrm{~mm}$ agg. & 3 & 20 & 207 \\
\hline $\mathrm{Lp}_{10} 30$ & $(\mathrm{PFA}+\mathrm{OPC}$ & 3 & 30 & 207 \\
\hline $\mathrm{Lp}_{10} 40$ & binder) & 3 & 40 & $204-210$ \\
\hline $\mathrm{Lp}_{20} 5$ & Limestone & 3 & 5 & 207 \\
\hline $\mathrm{Lp}_{20} 10$ & Concrete & 3 & 10 & 207 \\
\hline $\mathrm{Lp}_{20} 20$ & $20 \mathrm{~mm}$ agg. & 3 & 20 & 207 \\
\hline $\mathrm{Lp}_{20} 30$ & $(\mathrm{PFA}+\mathrm{OPC}$ & 3 & 30 & 207 \\
\hline $\mathrm{Lp}_{20} 40$ & binder) & 3 & 40 & $205-210$ \\
\hline $\mathrm{Bo}_{10} 5$ & Basalt & 3 & 5 & 220 \\
\hline $\mathrm{Bo}_{10} 10$ & Concrete & 3 & 10 & 220 \\
\hline $\mathrm{Bo}_{10} 20$ & $10 \mathrm{~mm}$ agg. & 3 & 20 & 220 \\
\hline $\mathrm{Bo}_{10} 30$ & (OPC & 3 & 30 & 220 \\
\hline $\mathrm{Bo}_{10} 40$ & binder) & 3 & 40 & 219-220 \\
\hline $\mathrm{Bo}_{20} 5$ & Basalt & 3 & 5 & 221 \\
\hline $\mathrm{Bo}_{20} 10$ & Concrete & 3 & 10 & 221 \\
\hline $\mathrm{Bo}_{20} 20$ & $20 \mathrm{~mm}$ agg. & 3 & 20 & 221 \\
\hline $\mathrm{Bo}_{20} 30$ & (OPC & 3 & 30 & 221 \\
\hline $\mathrm{Bo}_{20} 40$ & binder) & 4 & 40 & 219-224 \\
\hline $\mathrm{Bp}_{10} 5$ & Basalt & 3 & 5 & 220 \\
\hline $\mathrm{Bp}_{10} 10$ & Concrete & 3 & 10 & 220 \\
\hline $\mathrm{Bp}_{10} 20$ & $10 \mathrm{~mm}$ agg. & 3 & 20 & 220 \\
\hline $\mathrm{Bp}_{10} 30$ & $(\mathrm{PFA}+\mathrm{OPC}$ & 3 & 30 & 220 \\
\hline $\mathrm{Bp}_{10} 40$ & binder) & 3 & 40 & 218-220 \\
\hline $\mathrm{Bp}_{20} 5$ & Basalt & 2 & 5 & 221 \\
\hline $\mathrm{Bp}_{20} 10$ & Concrete & 3 & 10 & 221 \\
\hline $\mathrm{Bp}_{20} 20$ & $20 \mathrm{~mm}$ agg. & 3 & 20 & 221 \\
\hline $\mathrm{Bp}_{20} 30$ & $(\mathrm{PFA}+\mathrm{OPC}$ & 3 & 30 & 221 \\
\hline $\mathrm{Bp}_{20} 40$ & binder) & 5 & 40 & 219-224 \\
\hline BR40 & Basalt & 2 & 40 & - \\
\hline LR40 & Limestone & 3 & 40 & - \\
\hline
\end{tabular}

Table 4: Experimental programme and test specimens: Mortars and cement pastes.

\begin{tabular}{|c|c|c|c|c|}
\hline $\begin{array}{l}\text { Test/ } \\
\text { Spec. }\end{array}$ & $\begin{array}{l}\text { Material } \\
\text { Composi- } \\
\text { tion }\end{array}$ & $\begin{array}{c}\text { No. of } \\
\text { Repeats }\end{array}$ & $\begin{array}{l}\text { Int. } \\
\text { time } \\
(\mathrm{s})\end{array}$ & $\begin{array}{c}\text { Age } \\
\text { (days) }\end{array}$ \\
\hline Mo5 & Mortar & 3 & 5 & 234 \\
\hline Mo10 & (OPC & 3 & 10 & 232 \\
\hline Mo20 & binder) & 3 & 20 & 234 \\
\hline Mo30 & & 3 & 30 & 234 \\
\hline Mo40 & & 3 & 40 & $232-234$ \\
\hline Mo50 & & 2 & 50 & 238 \\
\hline Mo70 & & 1 & 70 & 238 \\
\hline Mp5 & Mortar & 3 & 5 & 234 \\
\hline Mp10 & $(\mathrm{PFA}+\mathrm{OPC}$ & 3 & 10 & 232 \\
\hline Mp20 & binder) & 3 & 20 & 234 \\
\hline Mp30 & & 3 & 30 & 234 \\
\hline Mp40 & & 3 & 40 & $232-234$ \\
\hline Mp50 & & 2 & 50 & 238 \\
\hline Mp70 & & 1 & 70 & 238 \\
\hline $\mathrm{P}_{42} 10$ & $\mathrm{PFA}+\mathrm{OPC}$ & 2 & 10 & 77 \\
\hline $\mathrm{P}_{42} 20$ & Paste & 2 & 20 & 77 \\
\hline $\mathrm{P}_{42} 30$ & $(w / b=0.42)$ & 2 & 30 & 77 \\
\hline $\mathrm{P}_{42} 40$ & & 2 & 40 & 72 \\
\hline $\mathrm{P}_{42} 70$ & & 2 & 70 & 77 \\
\hline $\mathrm{P}_{32} 10$ & $\mathrm{PFA}+\mathrm{OPC}$ & 2 & 10 & 77 \\
\hline$P_{32} 20$ & Paste & 2 & 20 & 77 \\
\hline $\mathrm{P}_{32} 30$ & $(w / b=0.32)$ & 2 & 30 & 77 \\
\hline $\mathrm{P}_{32} 40$ & & 2 & 40 & $71-73$ \\
\hline $\mathrm{O}_{42} 10$ & $\mathrm{OPC}$ & 2 & 10 & 77 \\
\hline $\mathrm{O}_{42} 20$ & Paste & 2 & 20 & 77 \\
\hline $\mathrm{O}_{42} 30$ & $(w / b=0.42)$ & 2 & 30 & 77 \\
\hline $\mathrm{O}_{42} 40$ & & 2 & 40 & $71-72$ \\
\hline $\mathrm{O}_{42} 70$ & & 2 & 70 & 77 \\
\hline $\mathrm{O}_{32} 10$ & OPC & 2 & 10 & 77 \\
\hline $\mathrm{O}_{32} 20$ & Paste & 2 & 20 & 77 \\
\hline $\mathrm{O}_{32} 30$ & $(w / b=0.32)$ & 2 & 30 & 77 \\
\hline $\mathrm{O}_{32} 40$ & & 2 & 40 & $71-72$ \\
\hline
\end{tabular}


Table 5: Specimen properties; $\mathrm{MC}=$ moisture content, $\mathrm{SR}=$ degree of saturation, Em.=emissivity, $\mathrm{Fc}=$ compressive strength (the mean of three repeats).

\begin{tabular}{lrrrr}
\hline Spec. & $\begin{array}{r}\text { Porosity } \\
(\%)\end{array}$ & $\begin{array}{r}\mathrm{MC} \\
(\%)\end{array}$ & $\begin{array}{r}\text { Density } \\
\left(\mathrm{kg} / \mathrm{m}^{3}\right)\end{array}$ & $\begin{array}{r}\mathrm{F}_{c} \\
(\mathrm{MPa})\end{array}$ \\
\hline \hline $\mathrm{Lp}$ & 12.4 & 5.0 & 2417 & 70 \\
$\mathrm{Lp}_{20}$ & & & & 68 \\
$\mathrm{Lo}$ & 11.0 & 4.5 & 2439 & 72 \\
$\mathrm{Lo}_{20}$ & & & & 67 \\
$\mathrm{Bp}$ & 14.2 & 5.7 & 2478 & 79 \\
$\mathrm{Bp}$ & & & & 75 \\
$\mathrm{Bo}_{20}$ & 12.2 & 4.7 & 2555 & 82 \\
$\mathrm{Bo}_{20}$ & & & & 86 \\
$\mathrm{Mp}$ & 21.1 & 9.3 & 2252 & 61 \\
$\mathrm{Mo}$ & 20.2 & 9.0 & 2250 & 61 \\
\hline $\mathrm{P}_{42}$ & 40.4 & 21.1 & 1908 & 54 \\
$\mathrm{P}_{32}$ & 33.0 & 16.4 & 2002 & 74 \\
$\mathrm{O}_{42}$ & 38.5 & 19.3 & 1993 & 64 \\
$\mathrm{O}_{32}$ & 31.9 & 15.2 & 2093 & 86 \\
\hline
\end{tabular}

material was used up to $1000{ }^{\circ} \mathrm{C}$ in air, using a heat rate of $10^{\circ} \mathrm{C} /$ minute. The samples used in DTA/TGA were crushed and ground (using pestle and mortar) until all material passed a $53 \mu \mathrm{m}$ sieve. Due to the heterogeneity of the concrete mixes, the DTA/TGA samples were not representative of the material as a whole, therefore, only DTA/TGA results of the cement pastes and mortars have been determined.

The experimental procedure used in this study is based on that determined in the first test series [2].

\subsection{Specimen properties}

The specimen properties detailed in Table 5, porosity, moisture content, density and compressive strength, follow the trend expected from evidence in the literature [8]. Hardened cement paste with a higher water/binder ratio and/or use of 25\% PFA replacement result in a weaker, more porous, less dense structure with a higher moisture content. Concretes and mortars using 25\% PFA replacement show a similar trend but to a lesser extent as the properties of the aggregates become more dominant.

\section{Volume removal and average surface temperature-time history results}

\subsection{Hardened cement pastes}

Volume removal results for all cement pastes tested in this study are shown in Figure 2a. For the same $w / b$ ratio the PFA + OPC paste experienced larger volume removals due to laser scabbling than that of the OPC

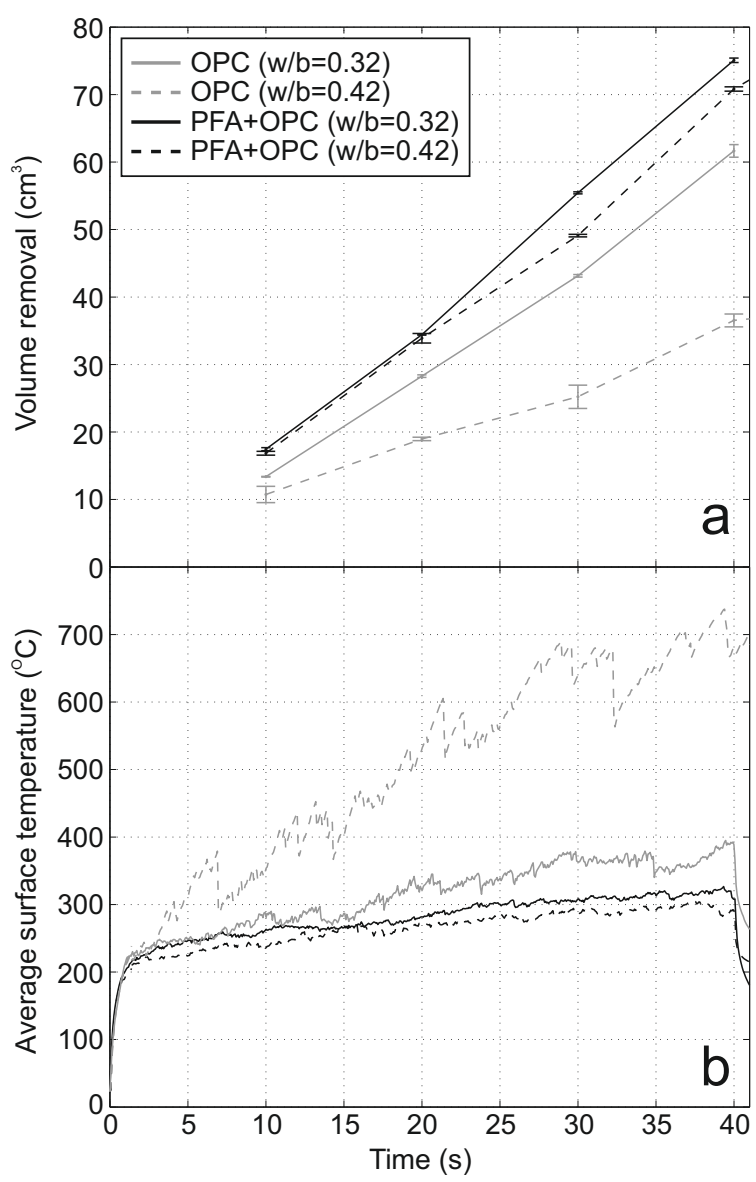

Figure 2: Cement pastes; (a) volume removal and (b) time histories of average surface temperatures for $\mathrm{OPC}_{42}, \mathrm{OPC}_{32}(\mathrm{PFA}+\mathrm{OPC})_{42}$ and $(\mathrm{PFA}+\mathrm{OPC})_{32}$ paste compositions.

pastes. The reduction in $w / b$ ratio from 0.42 to 0.32 resulted in a dramatic increase in the OPC paste (25-69\%, depending on interaction time), and marginally affected the volume removal of the PFA + OPC paste (4-13\%).

The time histories of average surface temperature in Figure $2 \mathrm{~b}$ show an almost identical temperature at the onset of scabbling $\left(\approx 220{ }^{\circ} \mathrm{C}\right)$, followed by different scabbling behaviour for the four compositions. After the onset of scabbling, the average surface temperature of the two PFA + OPC pastes continue to increase with a heat rate of around $2.5^{\circ} \mathrm{C} / \mathrm{s}$ with very small fluctuations (up to a maximum of around $20^{\circ} \mathrm{C}$ ). The $\mathrm{OPC}_{32}$ paste shows similar behaviour to the PFA + OPC pastes but with a higher constant heat rate of around $5{ }^{\circ} \mathrm{C} / \mathrm{s}$ and slightly larger temperature fluctuations (up to maximum of around $40{ }^{\circ} \mathrm{C}$ ). The average surface temperature is controlled by scabbling activity:as fragments are removed the average surface temperature is reduced by 
exposure of cooler areas. The low and steady rate of temperature increase in the two PFA + OPC pastes and $\mathrm{OPC}_{32}$ is a result of volume removal (Figure 2).

The $\mathrm{OPC}_{42}$ paste shows very different behaviour after the onset of scabbling: average surface temperature increases to $700{ }^{\circ} \mathrm{C}$ in the first $37 \mathrm{~s}$ (at a higher rate of about $13{ }^{\circ} \mathrm{C} / \mathrm{s}$ ), with larger (up to $120^{\circ} \mathrm{C}$ ), but less frequent, temperature fluctuations, as a result of lower rates of volume removal.

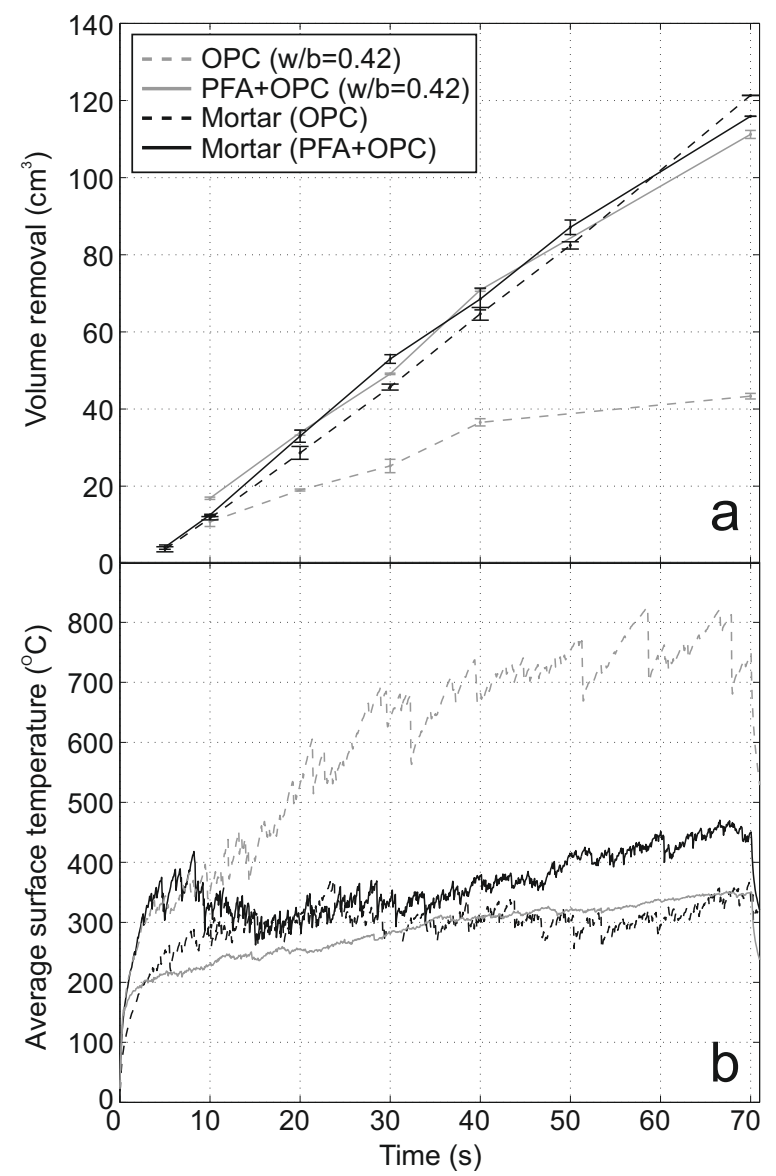

Figure 3: Mortars and cement pastes $(w / b=0.42)$; (a) volume removal and (b) time histories of average surface temperatures for the $\mathrm{OPC}_{42}$ and $(\mathrm{PFA}+\mathrm{OPC})_{42}$ paste compositions, and the $\mathrm{OPC}_{42}$ and (PFA + OPC) 42 mortar compositions.

The two cement pastes with $w / b=0.42$ were also exposed to $70 \mathrm{~s}$ interaction time (Figure 3 ). The results for the $(\mathrm{PFA}+\mathrm{OPC})_{42}$ show no change in behaviour after $40 \mathrm{~s}$, either in the rate of volume removal or in the rate of increase of average surface temperature. The rate of volume removal for the $\mathrm{OPC}_{42}$ drops dramatically between $40 \mathrm{~s}$ and $70 \mathrm{~s}$, from $0.9 \mathrm{~cm}^{3} / \mathrm{s}$ to $0.3 \mathrm{~cm}^{3} / \mathrm{s}$. The surface temperature reaches about $700{ }^{\circ} \mathrm{C}$ at $40 \mathrm{~s}$, and then oscillates around this value. The vitrification of the $\mathrm{OPC}_{42}$

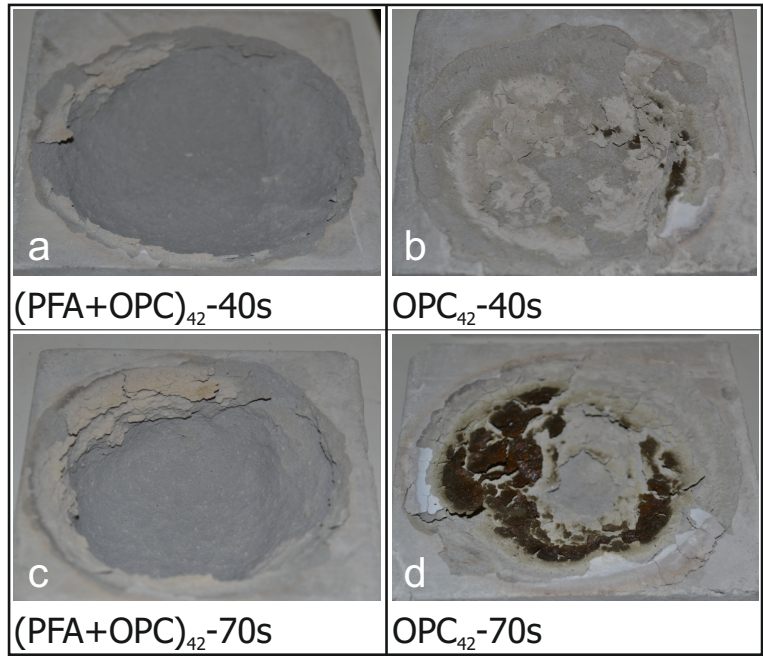

Figure 4: Photos of cement paste specimens after laser exposure, highlighting the extent of vitrification in $\mathrm{OPC}_{42}$ samples: (a) (PFA + $\mathrm{OPC}_{42}$ after $40 \mathrm{~s}$ exposure, (b) $\mathrm{OPC}_{42}$ after $40 \mathrm{~s}$ exposure, (c) (PFA $+\mathrm{OPC})_{42}$ after $70 \mathrm{~s}$ exposure, (d) $\mathrm{OPC}_{42}$ after $70 \mathrm{~s}$ exposure.

starts at about $40 \mathrm{~s}$ and develops further, covering almost $50 \%$ of the surface after $70 \mathrm{~s}$ (Figures $4 \mathrm{~b}$ and d). (PFA $+\mathrm{OPC})_{42}$ pastes show no vitrification for either $40 \mathrm{~s}$ or $70 \mathrm{~s}$ exposure (Figures $4 \mathrm{a}$ and $\mathrm{c}$ ).

\subsection{Mortars}

Figure 3 shows volume removals and average surface temperature histories of the mortar and cement pastes with the same $w / b$ of 0.42 . The difference between binder compositions is much less pronounced in the mortars than in the cement pastes. The $\mathrm{OPC}_{42}$ mortar did not experience a drop in rate of volume removal observed in the $\mathrm{OPC}_{42}$ paste (Figure $3 \mathrm{a}$ ). The two mortars show very similar volume removal rates to the (PFA + OPC) 42 paste.

The two mortars show different surface temperatures in the initial stage. Both the initial heating rate and the temperature at the onset of scabbling are higher for the mortar with PFA + OPC binder $\left(150{ }^{\circ} \mathrm{C} / \mathrm{s}\right.$ and $\left.300{ }^{\circ} \mathrm{C}\right)$ than those for the mortar with OPC binder $\left(110{ }^{\circ} \mathrm{C} / \mathrm{s}\right.$ and $240{ }^{\circ} \mathrm{C}$ ). To illustrate the repeatability of this result, Figure 5 shows all average surface temperatures recorded for the mortar specimens: one recording in the 0-550 ${ }^{\circ} \mathrm{C}$ temperature range for each composition (Figure $5 \mathrm{~b}$ ), and two recordings in the $200-2000{ }^{\circ} \mathrm{C}$ temperature range for each composition (Figure 5a). All three $\mathrm{OPC}_{42}$ mortar average surface temperature-time histories show a lower initial heat rate compared to the data for the $(\mathrm{PFA}+\mathrm{OPC})_{42}$ mortars. The results in Figure $3 \mathrm{~b}$ show that after the onset of scabbling, the two 


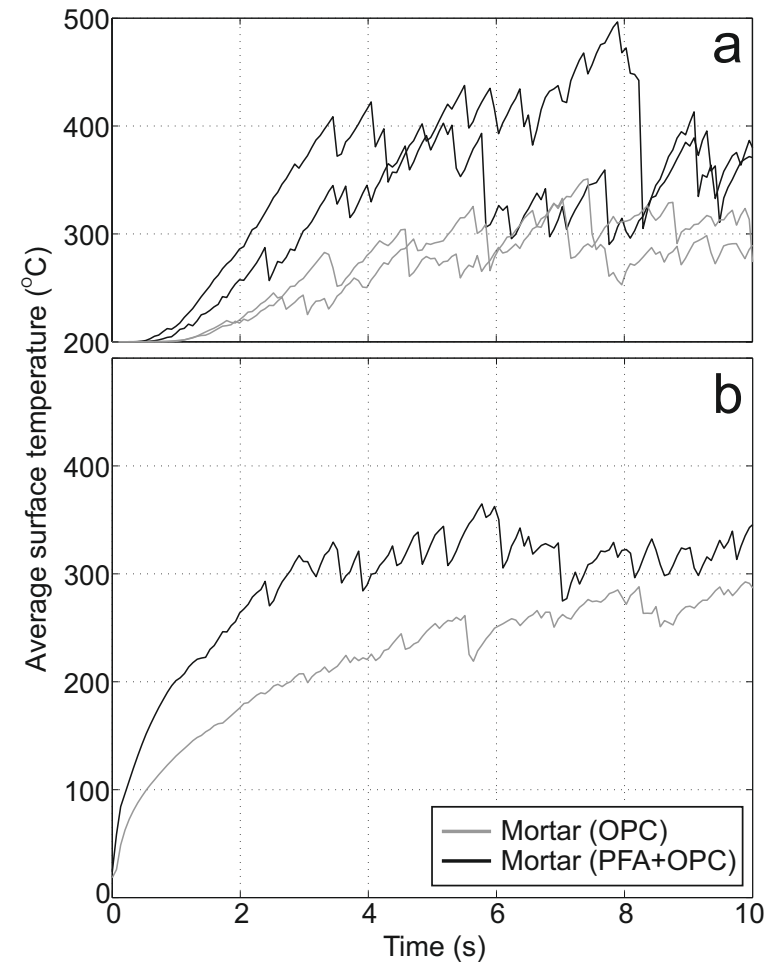

Figure 5: Mortars; time histories of average surface temperatures for the $\mathrm{OPC}_{42}$ and $(\mathrm{PFA}+\mathrm{OPC})_{42}$ mortar specimens. Both temperature ranges are included to highlight the repeatability of the reduced heat rate of the $\mathrm{OPC}_{42}$-mortar compared to the (PFA + OPC $)_{42}$-mortar.

mortars show almost identical average surface temperatures and temperature fluctuations until $35 \mathrm{~s}\left(\approx 300^{\circ} \mathrm{C}\right)$ , after which the temperature of PFA + OPC mortar increases at a rate of around $4{ }^{\circ} \mathrm{C}$ (to $450{ }^{\circ} \mathrm{C}$ after $70 \mathrm{~s}$ ), whereas the surface temperature of the OPC mortar remains nearly constant at $300{ }^{\circ} \mathrm{C}$.

Figure 3 shows that these differences in surface temperatures are reflected in the volume removal: the volume removal in the PFA + OPC mortar is larger at the beginning, and this difference remains almost constant for exposure intervals of up to $30 \mathrm{~s}$, when it starts reducing, and it is finally reversed for longer exposures (between $50 \mathrm{~s}$ and $70 \mathrm{~s}$ ), with a slightly larger volume removed from the OPC mortar after $70 \mathrm{~s}$ exposure as seen in Figure 3a. (It should be noted however, that there are no repeats of the tests using $70 \mathrm{~s}$ interaction time on the mortars).

\subsection{Concretes}

All concretes had lower volume removal than the mortars (Figure 6), with basalt concretes consistently showing lower volume removal than limestone concretes, and concretes with $(\mathrm{PFA}+\mathrm{OPC})_{42}$ binder show-

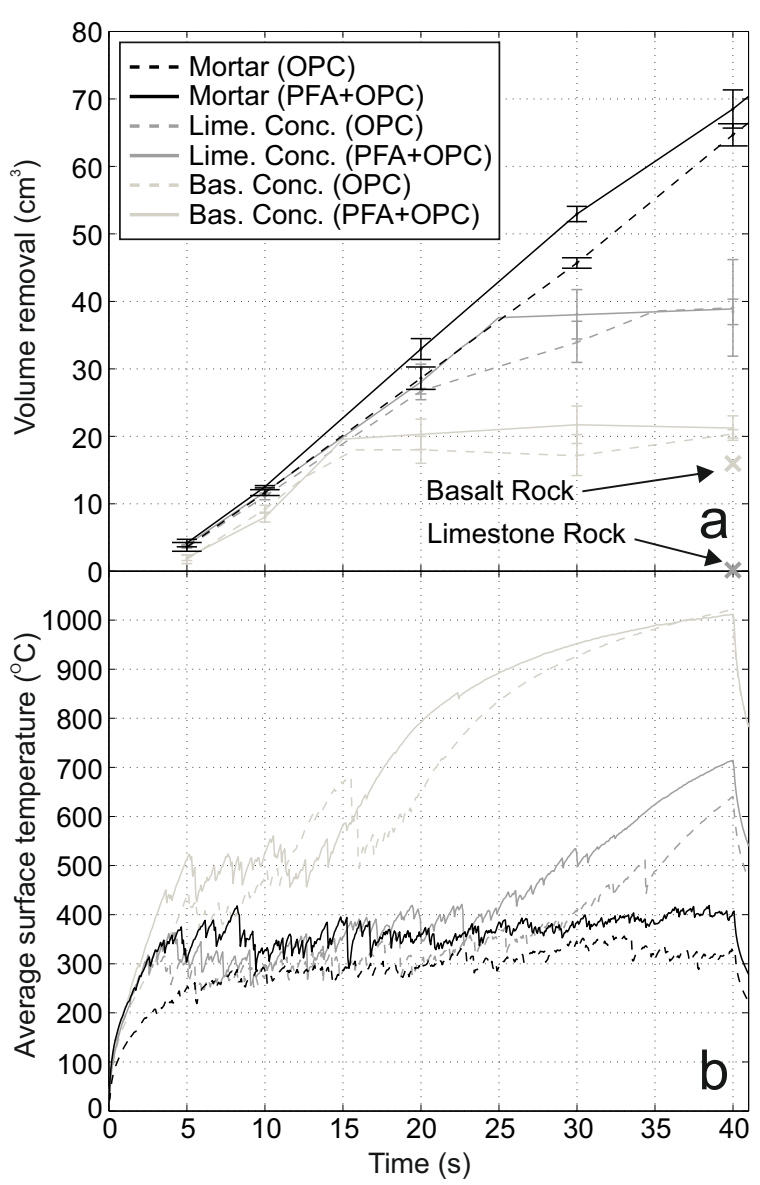

Figure 6: Concretes (10mm coarse aggregates) and mortars; (a) volume removal and (b) time histories of average surface temperatures for mortar, limestone concrete and basalt concrete compositions using both $\mathrm{OPC}_{42}$ and $(\mathrm{PFA}+\mathrm{OPC})_{42}$ binder compositions. Concretes made with $10 \mathrm{~mm}$ coarse aggregates.

ing $5-10 \%$ higher volume removal than concretes with $\mathrm{OPC}_{42}$ binder. All concretes undergo similar initial heat rates of around $100{ }^{\circ} \mathrm{C} / \mathrm{s}$ until the onset of scabbling, which differs at around $400-510{ }^{\circ} \mathrm{C}$ for the basalt concretes and $300{ }^{\circ} \mathrm{C}$ for the limestone concretes. Following this are the scabbling phases, which are very different for the concretes with different aggregates.

The surface temperature plot for the PFA + OPC basalt concrete shows scabbling activity until $15 \mathrm{~s}$ exposure with large fluctuations around an average surface temperature of $500{ }^{\circ} \mathrm{C}$ and volume removal rate of $1.7 \mathrm{~cm}^{3} / \mathrm{s}$, reaching a total of $20 \mathrm{~cm}^{3}$ (Figure 6). After this point the scabbling stops, the volume removal rate drops to zero, the average surface temperature increases to $1000{ }^{\circ} \mathrm{C}$ and the concrete vitrifies (Figure 7). It should be noted that the volume removal graphs (Figure 6a) were constructed using data recorded at $10 \mathrm{~s}$ and 


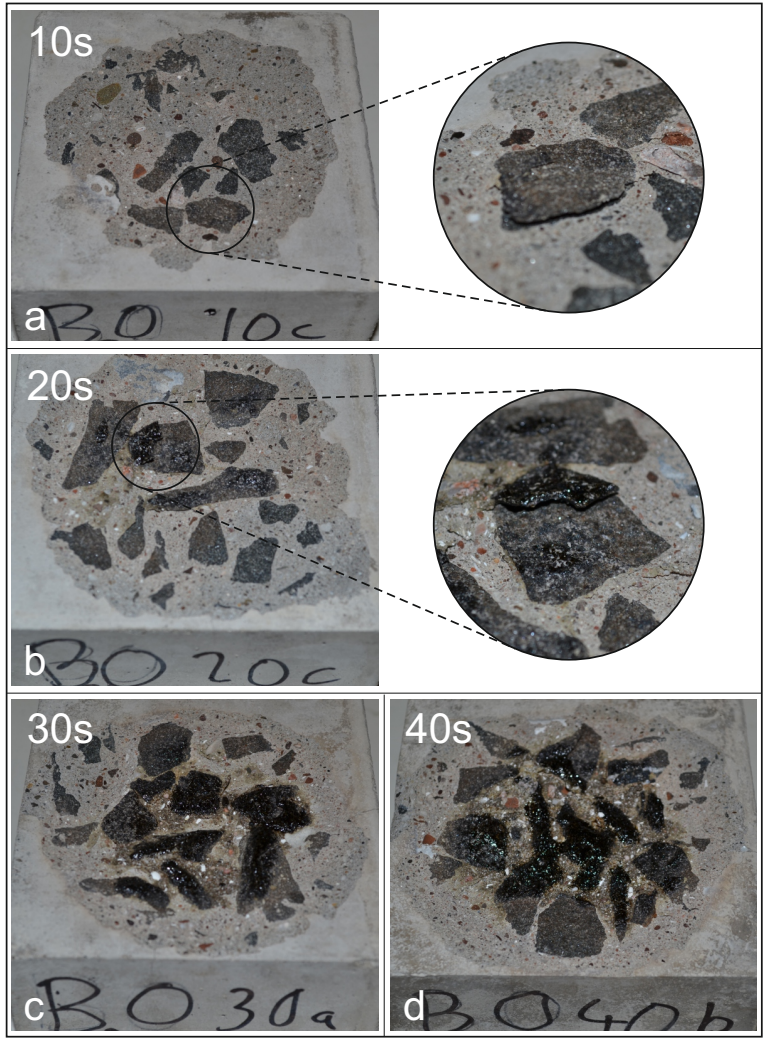

Figure 7: Photos after laser laser trials showing vitrification in basalt concrete $\left(\mathrm{Bo}_{20}\right)$ at different interaction times.

$20 \mathrm{~s}$. Hence the $15 \mathrm{~s}$ exposure as a point at which the rate of volume removal drops to zero was defined from the surface temperature graph (Figure 6b), which shows almost no temperature fluctuations after $15 \mathrm{~s}$ (a similar practice has been used for the limestone concrete). The OPC basalt concrete shows similar overall behaviour, but with a lower temperature at the onset of scabbling $\left(400{ }^{\circ} \mathrm{C}\right)$, and about 5-10\% lower volume removal.

The scabbling in the two limestone concretes shows two distinct phases. The first is the phase of temperature fluctuations around an almost constant temperature of $300{ }^{\circ} \mathrm{C}$ (Figure $6 \mathrm{~b}$ ) and constant volume removal rates (Figure 6a), which are different for the two limestone concretes: $1.7 \mathrm{~cm}^{3} / \mathrm{s}$, extending to $25 \mathrm{~s}$ exposure, for the PFA + OPC concrete; and $1.3 \mathrm{~cm}^{3} / \mathrm{s}$, up to 28 $\mathrm{s}$ exposure, for the OPC concrete. This is followed by short intervals (of about $5 \mathrm{~s}$ ) during which both limestone concretes exhibit reduced volume removal rates and small temperature fluctuations around an increasing average surface temperature (up to 30-35 s of exposure); and finally by $5-10$ s of zero volume removal rate and monotonic increase of surface temperature to 650- $700^{\circ} \mathrm{C}$ (between 30 and 40 s exposure time). The higher temperatures and higher volume removal were recorded for the PFA + OPC limestone concrete specimens (Figure 6).

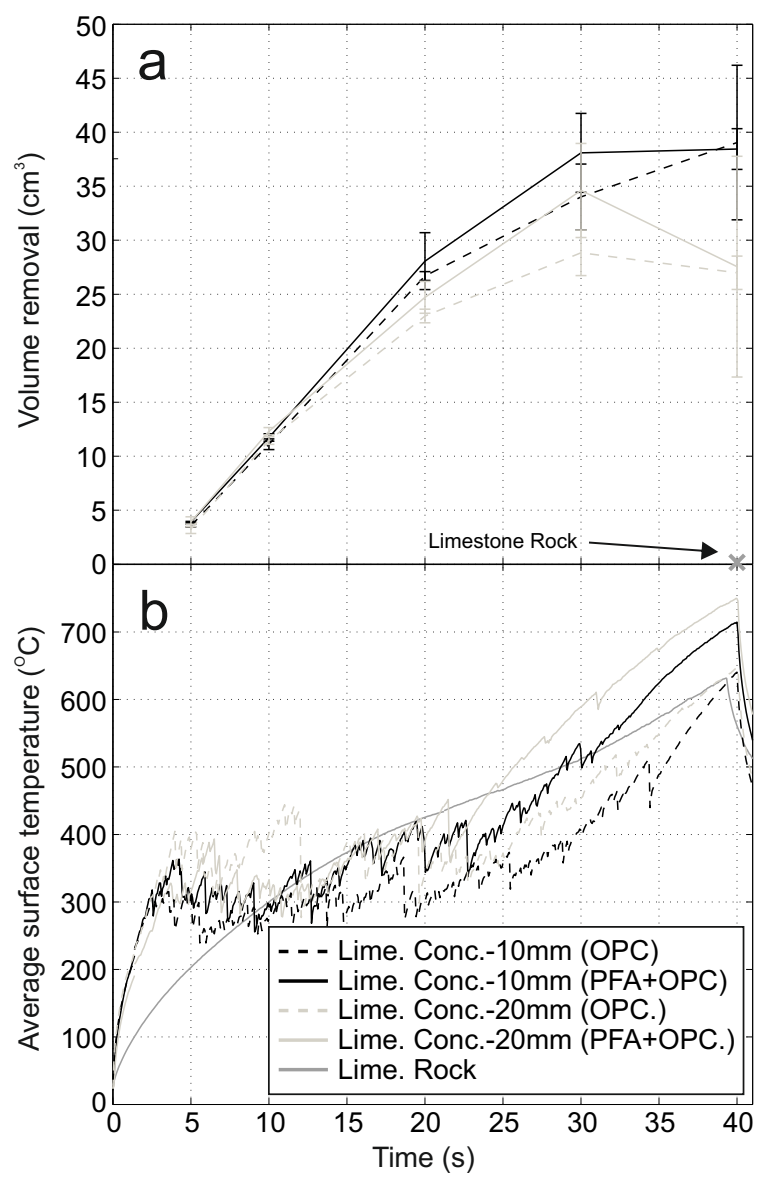

Figure 8: Limestone concretes and limestone rock; (a) volume removal and (b) time histories of average surface temperatures for the limestone concrete compositions using $10 \mathrm{~mm}$ and $20 \mathrm{~mm}$ coarse aggregates and $\mathrm{OPC}_{42}$ and $(\mathrm{PFA}+\mathrm{OPC})_{42}$ binder compositions. $40 \mathrm{~s}$ laser interaction on limestone rock specimens also included.

Figures 8 and 9 show the effect of aggregate size (10 $\mathrm{mm}$ vs $20 \mathrm{~mm}$ ) on scabbling behaviour of concretes (volume removal graphs and surface temperature histories), using both OPC and PFA + OPC, $w / b=0.42$. The effect of coarse aggregate size on volume removal was minimal with error margins overlapping in most cases. Regardless of type and size of aggregates, the concretes with OPC binder showed lower volume removal than those with PFA + OPC after 30s exposure, but this difference was reduced after 40s. The largest difference of $30 \%$ (reduced to $10 \%$ at $40 \mathrm{~s}$ ) was recorded for basalt concretes.

Concretes using larger aggregate sizes (Figure 9 for 


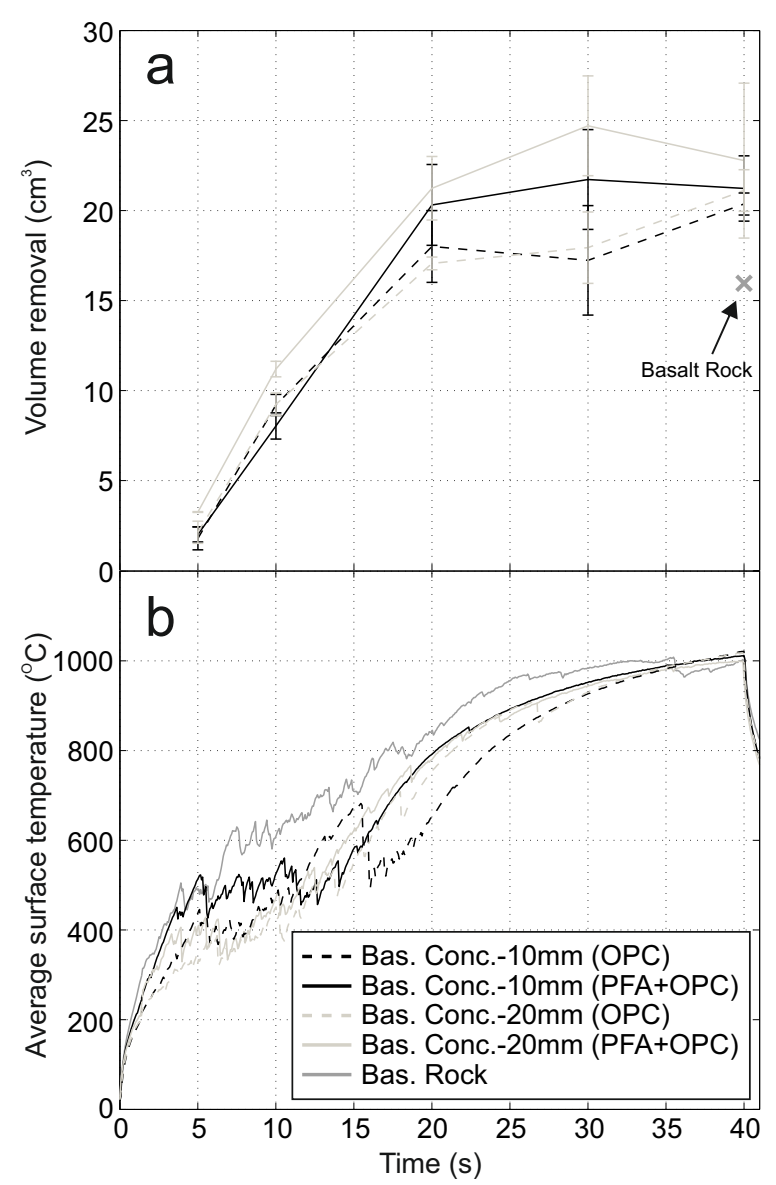

Figure 9: Basalt concretes and basalt rock; (a) volume removal and (b) time histories of average surface temperatures for the basalt concrete compositions using $10 \mathrm{~mm}$ and $20 \mathrm{~mm}$ coarse aggregates and the $\mathrm{OPC}_{42}$ and $(\mathrm{PFA}+\mathrm{OPC})_{42}$ binder compositions. $40 \mathrm{~s}$ laser interaction on basalt rock specimens also included.

basalt and Figure 8 for limestone) generally had slightly higher surface temperatures, but similar temperature fluctuation magnitudes.

\subsection{Rock specimens}

The tests on rock specimens show significant differences between basalt (Figure 9) and limestone (Figure 8). The limestone rock showed no evidence of scabbling in the average surface temperature-time history, and a much lower heat rate compared to all other compositions. The average surface temperature increases up to $470{ }^{\circ} \mathrm{C}$ after $25 \mathrm{~s}$ at a decreasing rate. After this, the heating rate starts increasing until the temperature reaches $640{ }^{\circ} \mathrm{C}$ at the end of the $40 \mathrm{~s}$ exposure interval (Figure $8 b$ ). Throughout this range there are no temperature fluctuations, which indicates that no scabbling occurred, and is also reflected in the negligible volume removal (Figure 8a). The inspection of the specimens at the end of the $40 \mathrm{~s}$ exposure showed a thin layer of white powder at the surface.

Basalt rock specimens (Figure 9b) underwent an initial heat rate comparable to the concretes of around 110 ${ }^{\circ} \mathrm{C} / \mathrm{s}$, before reaching an onset of scabbling at around $450{ }^{\circ} \mathrm{C}$, after $2 \mathrm{~s}$. The material underwent scabbling (Figure 9a) accompanied by a parabolic temperature increase, with fluctuations up to $800{ }^{\circ} \mathrm{C}(20 \mathrm{~s})$, followed by monotonic increase to $1000{ }^{\circ} \mathrm{C}$, when the heating rate approached zero. At this point the surface was fully vitrified. The total volume removal after $40 \mathrm{~s}$ was $16 \mathrm{~cm}^{3}$, or about $80 \%$ of the volume removal in basalt concrete.

\section{DTA/TGA results}

DTA, TGA and differential thermogravitimetric analysis (DTG) for the mortar and cement paste specimens are presented in Figure 10. The comparison between the DTA/TGA results of the control specimens (solid lines) and scabbled debris (dotted lines) have been used to identify the thermal reactions that have taken place during laser scabbling. The corresponding labels $(\mathrm{a}-\mathrm{h})$ are described in Table 6.

The extent of the difference between the debris and control samples generally follows the average surface temperature results: the TGA results of debris of compositions that experienced higher temperatures had lower mass loss than the control samples. A lower $w / b$ ratio and cement pastes including PFA (compared to those using only OPC which scabbled at lower temperatures) showed smaller differences between debris and control sample DTA/TGA results.

The DTA/TGA/DTG results suggest that cement pastes and mortars experienced free and interlayer moisture loss and decomposition of cement phases during scabbling. Discrepancies between results for the debris and the control samples of the mortars suggests that calcium hydroxide dehydroxylation ('e') and calcium carbonate decarbonation ('g'), and as a result, the $\alpha$-quartz to $\beta$-quartz inversion (' $\mathrm{f}$ ')), may have taken place to some extent. The decomposition of calcium hydroxide and calcium carbonate will increase pore pressures and decrease the tensile strength of the material. The quartz inversion could cause cracking increasing permeability and/or cause thermal stresses to develop and potentially be super-imposed [20] to the compressive forces which induce the shear forces required for thermal stress spalling to occur. 

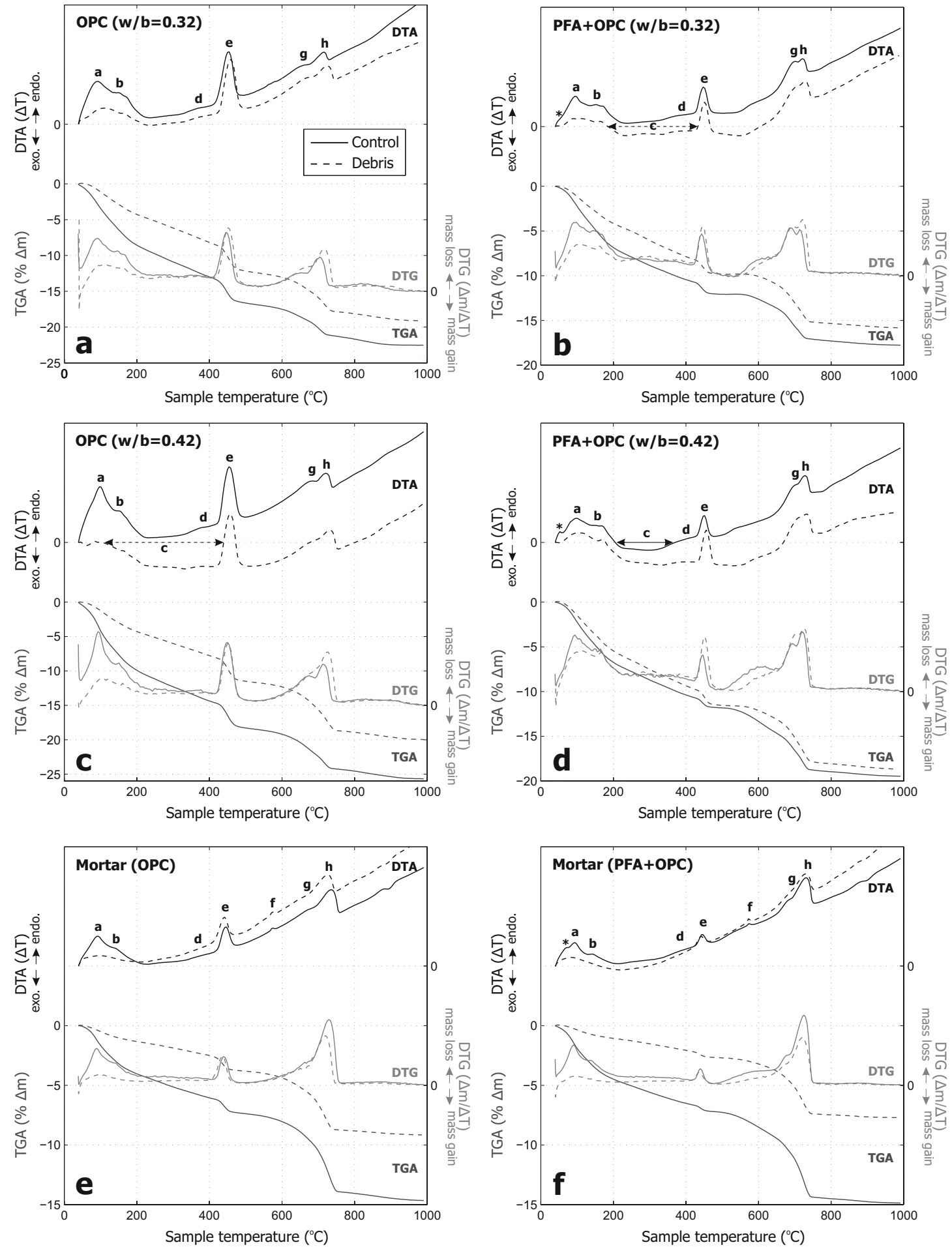

Figure 10: Graphical representation of DTA, TGA and DTG results of control specimens (solid lines) and debris (dotted lines) samples for (a) OPC $w / b=0.32$, (b) PFA + OPC $w / b=0.32$, (c) OPC $w / b=0.42$, (d) PFA + OPC $w / b=0.42$, (e) OPC mortar and (e) PFA + OPC mortar. 
Table 6: Thermal reactions highlighted in Figure 10, discussed in greater detail in [2].

\begin{tabular}{lll}
\hline & $\begin{array}{l}\text { DTA/TGA } \\
\text { representation }\end{array}$ & Thermal reaction responsible \\
\hline \hline 'a' & $\begin{array}{l}\text { Endothermic peak, } \\
\text { mass loss }\end{array}$ & $\begin{array}{l}\text { Evaporation of free and interlayer water. } \\
{[9,10,11,12]}\end{array}$ \\
\hline 'b' & $\begin{array}{l}\text { Endothermic peak, } \\
\text { mass loss }\end{array}$ & $\begin{array}{l}\text { Decomposition of cement phases (calcium monosulfoaluminate [13] } \\
\text { or calcium-hydrocarboaluminate [14]). }\end{array}$ \\
\hline 'c' & Exothermic behaviour & Potentially, oxidation of metallic impurities present in PFA. \\
\hline 'd' & $\begin{array}{l}\text { Endothermic hump, } \\
\text { slight mass loss }\end{array}$ & $\begin{array}{l}\text { Dehydration of hydration products such as calcium hydrosilicates, } \\
\text { calcium hydroaluminates and ettringite [14]. }\end{array}$ \\
\hline 'e' & $\begin{array}{l}\text { Endothermic peak, } \\
\text { mass loss }\end{array}$ & $\begin{array}{l}\text { Calcium hydroxide (portlandite) dehydroxylation } \\
{[12,15,16,17,18] .}\end{array}$ \\
\hline 'f' & $\begin{array}{l}\text { Endothermic peak, } \\
\text { no mass loss }\end{array}$ & $\begin{array}{l}\text { The reversible } \alpha \text {-quartz to } \beta \text {-quartz inversion [11, 19], which involves a } \\
\text { volume increase of } 0.85 \% \text { [8]. }\end{array}$ \\
\hline 'g' & $\begin{array}{l}\text { Endothermic peak, } \\
\text { mass loss }\end{array}$ & Decarbonation of calcium carbonate (vaterite). \\
\hline 'h' & $\begin{array}{l}\text { Endothermic peak, } \\
\text { mass loss }\end{array}$ & $\begin{array}{l}\text { Decarbonation of calcium carbonate (calcite) } \\
{[9,11,12,19] .}\end{array}$ \\
\hline$*$ & $\begin{array}{l}\text { Endothermic peak, } \\
\text { no mass loss }\end{array}$ & Unidentified structural change. \\
\hline
\end{tabular}

\section{Discussion of results}

The research literature identifies pore pressure and thermal stress as two key mechanisms responsible for explosive spalling [20, 21, 22, 23, 24, 25, 26, 27]. Pore pressure spalling is due to vaporisation of free, interlayer and/or chemically combined water causing a rapid increase in pore pressures which exceeds the tensile strength of the material. Thermal stress spalling is driven by the development of thermal stresses as a result of severe thermal gradients, caused by the high heat rates and low thermal conductivity of concrete. The process is also affected by differential thermal expansions between the constituents causing cracking which reduces both pore pressures and tensile strength. Since laser scabbling can be treated as a form of explosive spalling, albeit at much higher heating rates, the results of the experiments carried out in this study can be interpreted as a consequence of these three mechanisms.

\subsection{The effect of water/binder ratio}

It is widely accepted (e.g. [8]) that a reduction in $w / b$ ratios results in a denser and less porous cement matrix with higher strength and lower permeability. Lower permeability reduces mass migration and causes buildup of pore pressures. Higher strength has two effects: (i) maintains low permeability by delaying formation of cracks, and (ii) increases the tensile strain energy in the matrix; which both contribute to explosive ejection of material.

The results of this study show that laser scabbling was less effective on cement pastes with a higher w/b ratio of 0.42 , compared with pastes with $w / b=0.32$ (Figure $2 \mathrm{a}$ ). The clear difference is scabbling between the two OPC pastes indicates that the lower permeability and higher strength of the $w / b=0.32$ paste result in simultaneous increase in pore pressures and accumulation of elastic stresses, both leading to increased volume removal. The marginal difference in volume removal of the two PFA+OPC pastes however shows that the effect of different $w / b$ ratios on this type of paste is not so clear, and it requires further investigation, with a more detailed variation in both $w / b$ and $P F A / O P C$ ratios.

\subsection{The effect of PFA replacement}

Two effects of altering the binder composition of cement pastes can be identified from the volume removal and surface temperature time histories of the hardened cement pastes (Figure 2). The results show that (i) laser scabbling was more effective on PFA + OPC pastes than OPC pastes, regardless of the $w / b$ ratio, and (ii) the effect of the $w / b$ ratio on the PFA + OPC pastes was much smaller than that on the OPC pastes.

Increased scabbling of the PFA+OPC pastes was attributed to their reduced permeability, resulting in increased pore pressures during heating. As the PFA replacement was only one of the investigated factors, the 
permeability of the cement pastes was not investigated in detail and conclusions were made on the basis of available experimental evidence from literature. It is widely accepted that the use of PFA as a cement replacement material reduces the permeability of hardened cement pastes [8]. Results from a previous study [29] show that PFA+OPC pastes with 30\% PFA had lower permeability than OPC paste "even at the age of 28 days, prior to the major beneficial effects of the pozzolanic reactions". The scabbling tests in this study were performed at ages over 70 days, which was expected to contribute to a further reduction in permeability of the PFA+OPC paste. The specimens in this study were cured in water, which has also been found to reduce permeability $[29,30]$, with temperature-matched curing (as used in this study) introducing further reduction of permeability of pastes containing PFA [31]. The porosities measured in our tests show slightly higher values for PFA+OPC than the OPC pastes with the same $\mathrm{w} / \mathrm{b}$ ratios, which is in line with results reported in literature [32]. Higher porosity and lower permeability of $\mathrm{PFA}+\mathrm{OPC}$, compared to OPC paste, have been reported in the past $[32,33]$. This was explained by differences in the microstructure of PFA+OPC pastes, such as a combination of higher volume of larger pores with smaller pore entrances [32], as well as pore tortuosity, pore discontinuity and presence of adsorbed water in PFA+OPC pastes [33].

A reduction in permeability restricts the movement of gas causing pore pressures to build-up quicker and scabbling to take place at lower surface temperatures, through more frequent ejection of smaller fragments, as observed in the tests on OPC+PFA pastes (Figure 2.b). The fact that the largest volume removal was observed in the least permeable paste $(\mathrm{OPC}+\mathrm{PFA} 32)$ indicates that the pore pressure mechanism was the primary driver of laser scabbling of the hardened cement pastes. This is further supported by the DTA/TGA results (Figure 10) which suggest moisture loss and cement phase decomposition occurred in the debris of the paste during scabbling.

The effect of using PFA as a cement replacement material on volume removal during laser scabbling is less significant in the mortars and concretes compared to the hardened cement pastes due to the reduced paste content. The introduction of aggregates to the mix limits pore pressure spalling and affects the mechanical properties, allowing further mechanisms to take effect (such as thermal stress spalling and vitrification, discussed later).

One unexpected result was the significantly lower initial heating rate in $\mathrm{OPC}_{42}$ mortar compared to all the other materials (Figures $3 \mathrm{~b}$ and $6 \mathrm{~b}$ ). A more detailed comparison of the two mortars (three specimens of each) is shown in Figure 5.

\subsection{The effect of fine aggregates}

The volume removal of the $(\mathrm{PFA}+\mathrm{OPC})_{42}$ mortar is very similar to that of the $(\mathrm{PFA}+\mathrm{OPC})_{42}$ paste, whereas laser scabbling is far more effective on the $\mathrm{OPC}_{42}$ mortar compared to the $\mathrm{OPC}_{42}$ paste (Figure 3a). The increased volume removal during laser scabbling due to the addition of fine aggregates, as is the case with the $\mathrm{OPC}_{42}$ mortar, cannot be explained by the pore pressure mechanism. The replacement of water rich cement paste with anhydrous sand particles ( $56 \%$ by mass), and the creation of highly porous interfacial transition zones between the aggregates and cement paste [8], will result in a reduction of pore pressure spalling. The reduced effect of the permeability of the paste is supported by the fact that binder composition had much less effect on volume removal in the two mortars compared to the hardened cement pastes. The DTA/TGA results for mortars (Figures 10.e and 10.f), show similar changes in the debris, such as moisture loss (point "a") and cement phase decomposition (point "e") to these in the cement pastes. These processes however, have very little influence on the volume removal and overall scabbling behaviour of the two mortars (Figure 3).

An alternative mechanism driving the scabbling could be stresses produced by thermal gradients in the material. The scabbling would occur by accumulation of stresses in a volume of material that expands more than the surrounding cooler material, until they reach the strength (shear and tensile) at the boundaries of that volume, after which the accumulated strain energy will eject the fragment [20]. The overall scabbling behaviour is presented through time histories of volume removal (Figure 3.a) and average surface temperature (Figure 3.b). The thermal images for each time step however, show temperature differences within the affected surface area, indicating development of thermal gradients in certain zones prior to the fragment ejection, and a sudden drop in temperature in these zones after the ejection. In cement pastes the zones of temperature fluctuations are small and evenly distributed across the surface; whereas in mortars, they are developing over fewer and larger areas. This results in different sizes of debris and different histories of fluctuations in the average surface temperature. The analysis of the debris shows that in mortars the scabbling occurs through larger and thicker fragments, incorporating a number of grains, which indicates that this mechanism is predominant in mortars. 


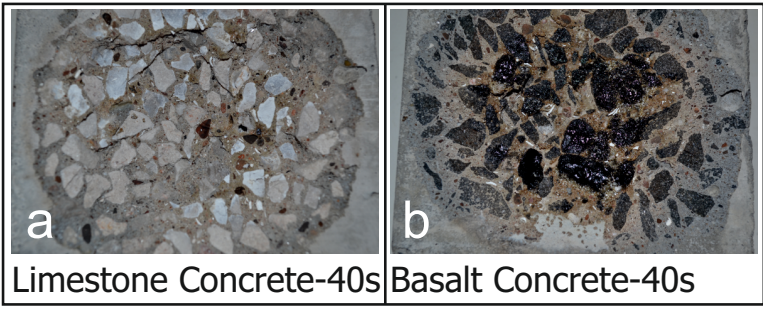

Figure 11: Photos of specimens after 40s of laser interaction; (a) limestone concrete showing decarbonated limestone aggregates (whiter, brighter aggregates) and vitrification of mortar surrounding aggregates (light brown rather than grey); and (b) basalt concrete showing vitrification of basalt aggregates (darker, glossier aggregates).

This is reflected in the time histories of surface temperature and volume removal: the volume removal histories for mortars are similar to these for PFA+OPC pastes (Figure 3.a), but the average surface temperature fluctuations in mortars are larger and less frequent (Figure 3.b).

Without the reinforcement provided by the fine aggregates (sand grains), the low tensile strength of the cement paste would result in fracturing without accumulation of strain energy. This would result in damaged material remaining at the surface and getting hotter, until eventually there is enough strain energy (or pore pressure) in the deeper layers to force an occasional ejection of the surface material. This corresponds to the scabbling behaviour observed in $\mathrm{OPC}_{42}$ paste. In the case of $(\mathrm{PFA}+\mathrm{OPC})_{42}$ paste (and the pastes with $\mathrm{w} / \mathrm{b}=0.32$ ) the lower permeability causes pore pressure spalling to occur before the development of thermal stresses, resulting in frequent ejection of smaller fragments.

\subsection{The effect of coarse aggregates}

At interaction times of up to $20 \mathrm{~s}$, volume removal in concretes is similar to that of the mortars (Figure 6a). The distribution of aggregates within concrete means that material removed in the early stages would be mostly mortar and as a result concretes will behave like mortars until the coarse aggregates are exposed. The final depth of scabbling in the concretes (a maximum of $15 \mathrm{~mm}$ ) may be too small for the full effect of the larger $20 \mathrm{~mm}$ aggregates to take place, potentially explaining the similarities in scabbling behaviour between the 10 $\mathrm{mm}$ and $20 \mathrm{~mm}$ aggregate concretes (Figures 8 and 9).

The reduction in rate of volume removal experienced by the concrete compared to mortar specimens and cement pastes (Figure 6a), suggests that the presence of coarse aggregates limits the effectiveness of laser scabbling. This reduction in rate of volume removal must be the result of either a reduction in the driving force responsible for laser scabbling, an increase in the resistance to scabbling or the introduction of a further mechanism which hinders scabbling.

The replacement of mortar with coarse aggregates reduces the amount of free water in the material by 40$50 \%$ (Table 5) and the chemically combined water (due to a reduction in cement paste content), consequently the effects of pore pressure spalling are reduced. The higher compressive strength of the concretes compared to the mortars (Table 5), along with the local reinforcing effect of the coarse aggregates, would result in higher tensile strength of the concretes than the mortars, increasing the resistance to scabbling. It could be assumed that after the intial scabbling of the surface layer, when the aggregates are fully exposed, the thermal stresses would not always be sufficient to cause either fracture of the aggregates or ejection of whole aggregate pieces, and the thermal stress spalling will be greatly reduced. The reduction in both pore pressure spalling and thermal stress spalling will reduce the rate of volume removal, resulting in rapid increase in surface temperatures, which is exactly the scabbling behaviour displayed by the two concretes observed in the tests (Figure 6).

Despite the basalt rock scabbling to a greater extent than the limestone rock, limestone concrete scabbles more than the basalt concrete (Figure 6a). The average surface temperature histories show the temperature of the basalt rock to be higher (Figure 9) than limestone rock (Figure 8), despite the larger volume removal in basalt rock. This could be due to higher reflectivity of limestone rock than basalt rock, something that needs to be investigated further.

The small volume removal of solid limestone rock (Figure 8a), suggests that the properties of limestone aggregates do not directly enhance laser scabbling. The lower volume removal of the limestone concrete compared to the mortar specimens is a direct result of reducing the content of mortar with rock, reducing the available driving force. This effect does not take place until the surface mortar is removed and the coarse aggregates are fully exposed. At longer interaction times (30-40 s) the rate of volume removal in the limestone concretes is reduced to zero and the average surface temperatures increase rapidly to $650-700{ }^{\circ} \mathrm{C}$ (Figure $8 b$ ), resulting in a limited amount of vitrification in the mortar surrounding the aggregates, and decarbonation of the limestone aggregates (Figure 11a).

The tests on basalt rock showed scabbling of thin flakes of material (Figure 12a) in a similar fashion to the spalling of granite blocks observed during tests reported by Zhang et al [34]. After 20s of scabbling the 

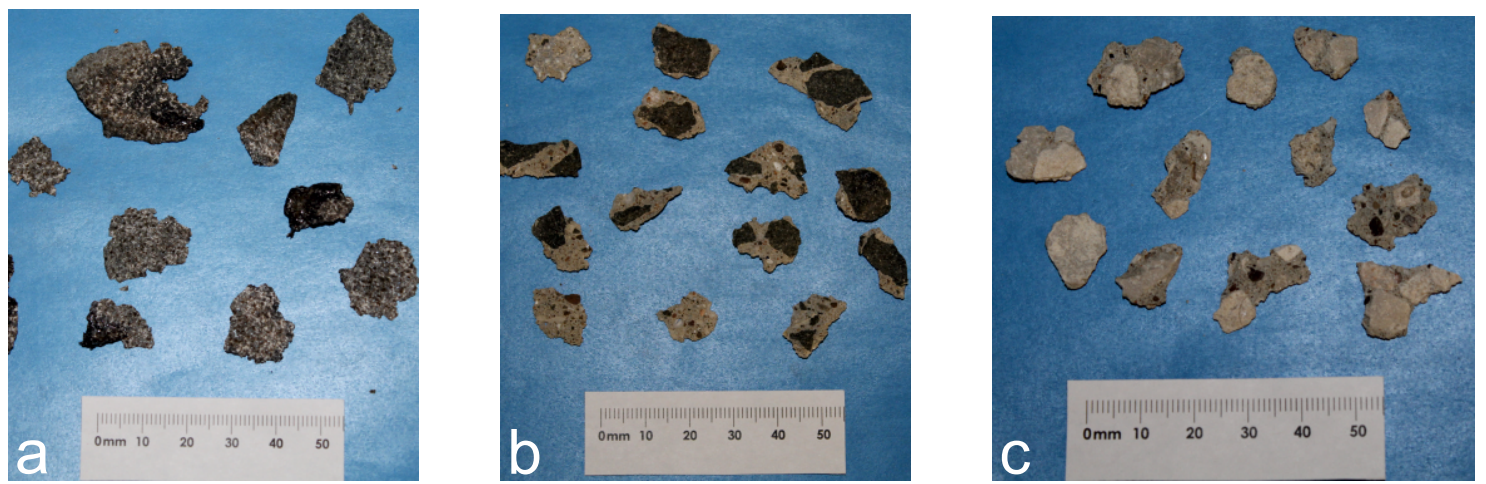

Figure 12: Photographs of laser scabbling debris (a) basalt rock, (b) OPC basalt concrete and (c) OPC limestone concrete compositions. It should be noted that debris collected is not representative of that initially ejected as it is damaged after ejection (before collection).

basalt rock underwent full vitrification. High speed photography of the process shows that basalt aggregates in the concrete specimens scabbled in a similar manner, as well as in bulk fragments (Figure 12b) including aggregate and mortar, similar to the limestone concrete (Figure 12c). The volume removal in basalt concrete is lower than that in mortar even in the early stages of the process. This is a result of the early stage vitrification of the basalt aggregates, in addition to the reduction in the mortar content and the increase in resistance (strength and reinforcement).

Figure 7a shows evidence of basalt aggregate undergoing partial scabbling in the early stages $(10 \mathrm{~s}$ exposure), leaving the aggregate fragmented. The fragmented aggregate is unable to develop thermal stresses and as a result would only be removed if the material beneath it was ejected. In this case, the fragmented aggregate blocks the laser radiation, keeping it from reaching the material beneath, leaving the fragmented aggregate prone to vitrification (Figure $7 \mathrm{~b}$ ). The phase change that takes place during vitrification uses up energy from the system that may otherwise increase thermal stresses. Vitrified areas increase the temperature locally, inducing further vitrification of nearby aggregates and mortar, reducing the rate of scabbling further. While large areas of vitrified material were seen to scabble (Figure 13) and vitrified material was identified in the debris in the early stages $(<15 \mathrm{~s})$, when the concrete is exposed to longer interaction times a drop in the rate of volume removal coincides with an increase in vitrification (Figure $7 \mathrm{c}$ and $d$ ).

\subsection{Repeatability}

In previous laser scabbling $[3,4,5,6]$ and explosive spalling [20] experiments researchers reported stochas- tic behaviour. Identical specimens exposed to identical conditions exhibited different results. These studies $[3,4,5,6]$ do not report on details of specimen preparation (such as curing and storage) or key material characteristics of the specimens before the tests (porosity, moisture content, density or strength). The source of poor repeatability could have been the variability of the tested materials due to the lack of control over the process of specimen preparation. In this study no stochastic behaviour has been identified. The largest variations in volume removal, recorded in the most variable specimens (concrete using $20 \mathrm{~mm}$ aggregate), were still small enough to enable clear distinction between the tested materials (Figure 6). The variations in cement pastes and mortars were even smaller (Figure 3 ).

\section{Conclusions}

The results from this study can be used to make the following conclusions on the mechanism(s) of laser scabbling:

1. The main cause of laser scabbling in cement pastes is pore pressure spalling driven by vaporisation of free, interlayer and/or chemically combined water in the cement matrix. The results show a clear relationship between strength, porosity and permeability and volume removal in OPC paste, but the effect of these factors was far less significant in the paste with $\mathrm{PFA}+\mathrm{OPC}$ binder $(\mathrm{PFA}+\mathrm{OPC}=25 \%+75 \%)$.

2. The dominant mechanism for scabbling of mortars is a combination of thermal stress spalling and pore pressure spalling (which is reduced due to the reduction of available water in the mortars compared to the cement pastes); 


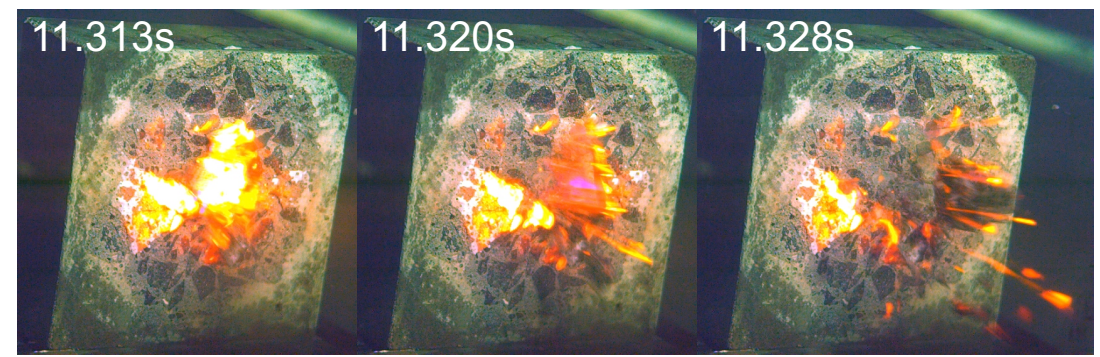

Figure 13: High speed photography of basalt concrete showing vitrified areas (glowing white) being scabbled.

3. The primary driving force for laser scabbling of concretes is developed from the mortar not the coarse aggregates;

4. The low melting point of basalt rock causes vitrification, which hinders laser scabbling of basalt concrete;

5. The decarbonation of limestone aggregates causes weakening/powdering of the rock, which hinders laser scabbling of limestone concrete.

This study has highlighted the following practical considerations for the laser scabbling process:

1. Laser scabbling of cement pastes is generally more effective when using a lower $w / b$ ratio and/or PFA replacement. However, due to the reduced effect of $w / b$ ratio on the behaviour of the tested $\mathrm{PFA}+\mathrm{OPC}$ paste, further investigation is required to isolate the two effects ( $w / b$ and $P F A / O P C$ ratios).

2. If a material is not scabbling at a sufficient rate vitrification and/or decarbonation will take place;

3. Limits on laser interaction times exist for concrete specimens, above which no further laser scabbling will take place. For the laser parameters used in this study (beam diameter $=60 \mathrm{~mm}$, power $=5 \mathrm{~kW}$ ), interaction time on limestone concrete should not exceed $25 \mathrm{~s}$ (equivalent to a minimum scan speed $=144 \mathrm{~mm} / \mathrm{min}$ ) and $15 \mathrm{~s}$ (minimum scan speed $=240 \mathrm{~mm} / \mathrm{min}$ ) for basalt concrete.

It should also be noted that previously reported stochastic behaviour was not identified in this study.

\section{Acknowledgements}

The authors would like to thank the UK Engineering and Physical Sciences Research Council (EPSRC) for the financial support for this study and the EPSRC Engineering Instrument Pool for lending the equipment (FLIR SC640 and the Phantom V5.1) used in this study.
The authors are also grateful to CEMEX UK and Longcliffe Ltd for providing aggregates for the test specimens.

\section{References}

[1] S. Burke, Concrete decontamination. a literature review, Technical report AEEW-R-2609, Winfrith, United Kingdom Atomic Energy Authority, Winfrith (March 1990).

[2] B. Peach, M. Petkovski, J. Blackburn, D. Engelberg, An experimental investigation of laser scabbling of concrete, Construction and Building Materials 89 (2015) 76-89.

[3] L. Nguyen, Removal of surface concrete with high power yb fibre lasers, Technical report 17800/1/07, TWI Ltd, Granta park, Cambridge (October 2007).

[4] P. Hilton, Scabbling of dry and wet concrete and submerged concrete, Technical report 18039/1/08, TWI Ltd, Granta park, Cambridge (December 2008).

[5] P. Hilton, The potential of high power lasers for concrete scabbling and pipe cutting in nuclear decommissioning, Technical report 19124/1/10, TWI Ltd, Granta park, Cambridge (March 2010).

[6] D. MacCallum, J. Norris, Laser concrete ablation scaling effects., in: ICALEO : 27 th international congress on applications of lasers and electro-optics., Laser Institute of America (2008) 143-149.

[7] British Standards Institution, Testing hardened concrete. Part 7: Density of hardened concrete BS EN 12390-7:2009, (2009).

[8] A. Neville, Properties of concrete. 4th and final ed, Harlow, UK: Pearson Education Limited, 1997.

[9] ASTM, Standard practice for petrographic examination of hardened concrete, ASTM C856-1995 (1995).

[10] H. Hilsdorf, A method to estimate the water content of concrete shields, Nuclear Engineering and Design 6 (3) (1967) 251-263.

[11] U. Schneider, U. Diederichs, C. Ehm, Effect of temperature on steel and concrete for pcrv's, Nuclear Engineering and Design 67 (2) (1982) 245-258.

[12] E. Stepkowska, J. Blanes, A. Justo, M. Aviles, J. PerezRodriguez, Thermo xrd-analysis of two aged cement pastes, Journal of Thermal Analysis and Calorimetry 80 (1) (2005) 193-199.

[13] I. Odler, S. Abdul-Maula, Possibilities of quantitative determination of the aft-(ettringite) and afm-(monosulphate) phases in hydrated cement pastes, Cement and Concrete Research 14 (1) (1984) 133-141.

[14] V. Lilkov, O. Petrov, Y. Tzvetanova, P. Savov, Mössbauer, dta and xrd study of portland cement blended with fly ash and silica fume, Construction and Building Materials 29 (2012) 33-41. 
[15] L. Alarcon-Ruiz, G. Platret, E. Massieu, A. Ehrlacher, The use of thermal analysis in assessing the effect of temperature on a cement paste, Cement and Concrete Research 35 (3) (2005) 609613.

[16] T. Harmathy, Thermal properties of concrete at elevated temperatures, Journal of Materials 5 (1) (1970) 47-74.

[17] G. Khoury, B. Grainger, P. Sullivan, Transient thermal strain of concrete: literature review, conditions within specimen and behaviour of individual constituents, Magazine of Concrete Research 37 (132) (1985) 131-144.

[18] W. Dias, G. Khoury, P. Sullivan, Mechanical properties of hardened cement paste exposed to temperatures up to $700 \mathrm{c}$ (1292 f), ACI Materials Journal 87 (2) (1990) 160-166.

[19] K. Blair, The interaction of $\mathrm{co}_{2}$ lasers with concrete and cement materials, Ph.D. thesis, University of Liverpool, Liverpool (June 1996).

[20] G. Khoury, Y. Anderberg, Concrete spalling review, Technical report, Swedish National Road Administration (June 2000).

[21] L. A. Ashton, S. Bate, Fire resistance of prestressed concrete beams, in: ACI Journal Proceedings, Vol. 57, ACI (1961).

[22] Y. Fu, L. Li, Study on mechanism of thermal spalling in concrete exposed to elevated temperatures, Materials and structures 44 (1) (2011) 361-376.

[23] Z. P. Bazant, G. Cusatis, Concrete creep at high temperature and its interaction with fracture: recent progress, in: Creep, shrinkage and durability of concrete and concrete structures: CONCREEP 7: September 12-14, Nantes, France, Laser Institute of America (2005), 143-149.

[24] R. Jansson, L. Boström, The influence of pressure in the pore system on fire spalling of concrete, Fire technology 46 (1) (2010) 217-230.

[25] J.-C. Mindeguia, H. Carré, P. Pimienta, C. La Borderie, Experimental discussion on the mechanisms behind the fire spalling of concrete, Fire and Materials (2014).

[26] Y. Sertmehmetoglu, On a mechanism of spalling concrete under fire conditions, Ph.D. thesis, University of London, London (July 1977).

[27] J. Dougill, The effects of high temperature on the strength of concrete with reference to thermal spalling, Ph.D. thesis, Imperial College London (1971).

[28] B. Lothenbach, K. Scrivener, R. Hooton, Supplementary cementitious materials, Cement and Concrete Research 41 (12) (2011) 1244-1256.

[29] R. K. Dhir, E. A. Byars, Pulverised fly ash concrete: intrinsic permeability. ACI Materials Journal 90(6) (1993) 571-580.

[30] M. D. A. Thomas, J. D. Matthews, The permeability of fly ash concrete. Materials and Structures 25 (7), (1992) 388-396

[31] A. A. Ramezanianpour, V. M. Malhotra, Effect of curing on the compressive strength, resistance to chloride-ion penetration and porosity of concretes incorporating slag, fly ash or silica fume. Cement and Concrete Composites 17 (2), (1995) 125-133.

[32] F. Massazza, Pozzolanic cements. Cement and Concrete Composites 15(4), (1993) 185-214.

[33] D. C. Hughes, Pore structure and permeability of hardened cement paste. Magazine of Concrete Research 37 (133), (1985) 227-233

[34] P. Zhang, E. Nordlund, G. Mainalia, C. Saiang, R. Jansson, B. Adl-Zarrabi, Experimental study of thermal spalling of rock blocks exposed to fire, Bergmekanik I Norden (2010) 9-12. 